We PA1 27

\title{
A Seismic Processing Approach Dedicated to Quantitative Characterization of Landfill Heterogeneities
}

\author{
L.A. Konstantaki* (Delft University of Technology), R. Ghose (Delft \\ University of Technology), D. Draganov (Delft University of Technology), \\ G. Diaferia (Deltares, The Netherlands) \& T. Heimovaara (Delft University \\ of Technology)
}

\section{SUMMARY}

The ability to image and quantify the heterogeneity in municipal landfills is crucial for improving the landfill treatment methods, for predicting the behaviour of processes that take place inside the landfills and hence, for estimating the after-care period. Our aim is to image the flow paths inside landfills and to quantify the heterogeneity. We develop a new methodology using both seismic reflection and electrical resistivity methods. We illustrate the possibility of imaging wet and dry pockets inside a landfill and provide density and porosity distributions that are important input parameters to models that predict the behaviour of landfills. 


\section{Introduction}

A key factor affecting the treatment of landfills is the heterogeneity inside the landfill body (Powrie and Beaven 1999). When the landfill is treated as a bioreactor (e.g., with recirculation of leachate or water), the flow and air paths, which are determined by density and porosity heterogeneities, need to be mapped and understood in detail. In this research, we focus on using geophysical methods to image and characterize the preferential flow paths inside the landfill. We propose a new approach that combines seismic reflection and electrical resistivity (ER) methods to image the possible wet and dry pockets inside the landfill and provide density and porosity distributions.

Models that can predict the behaviour of the processes inside a landfill over a period of time, need detailed density information (McDougall and Fleming 2013). Porosity is another important factor affecting the treatment of landfills; the distribution of porosity needs to be defined (Staub et al. 2009). Using dedicated seismic reflection processing steps, it is possible to provide information on density and porosity distributions that can help to define the after-care period of a landfill and to improve the treatment procedure so that the after-care period is reduced. But geophysical studies aimed at imaging and characterizing landfills face serious challenges such as noise in the data and artifacts (De Iaco et al. 2003, Jolly et al. 2011). In the following we present a methodology, which shows how these challenges can be overcome.

\section{Data acquisition}

In the summer of 2013 we acquired seismic reflection and ER data in the Wieringermeer landfill in the Netherlands. For seismic reflection data we used a shear-wave (S-wave) high-frequency vibrator (Ghose et al. 1996) source and $48 \mathrm{~S}$-wave geophones at a $0.5 \mathrm{~m}$ spacing. The source spacing was $1 \mathrm{~m}$, starting shooting at $4 \mathrm{~m}$ before the first geophone and ending at $4 \mathrm{~m}$ after the last geophone. The parameters for vibroseis data acquisition were as follows: a sampling interval of $0.5 \mathrm{~ms}$, a $20-300 \mathrm{~Hz}$ sweep, a record length of $4200 \mathrm{~ms}$ and a sweep length of $3200 \mathrm{~ms}$ (resulting in a trace length of 1000 ms after vibrogram compression). Deterministic source signature deconvolution (Ghose 2002, Ghose 2012) was performed to compress the raw vibrograms. We performed electrical resistivity measurements using Wenner and dipole-dipole geometries. We used 64 electrodes at $1 \mathrm{~m}$ spacing, trying to reach at least down to $15 \mathrm{~m}$ depth, where the bottom of the landfill was expected. The Wenner measurements had a total recording time of 30 minutes, whereas the dipole-dipole measurements took 60 minutes. The seismic and ER measurements were coincident.

\section{Seismic reflection data processing}

Figure 1a shows an example of the shot at $23 \mathrm{~m}$ (shot 23) after vibroseis deconvolution. We apply an automatic gain control with a $30 \mathrm{~ms}$ window. Our data suffer from strong surface waves coming from another source (gas pipe, road traffic or human activity in a nearby building), and therefore, we look at the first $400 \mathrm{~ms}$ of data only. The surface waves exhibit similar velocities and frequencies to reflection and diffraction events, making it difficult to remove them by conventional spatial filtering. We mute the surface waves shot by shot, taking special care that the remaining events are body-wave signals and they can be tracked in successive shots. We realize that in seismic reflection data processing at noisy landfill sites, one key point is to focus on only the true events that come from the heterogeneities in the landfill body. This is crucial for a high-resolution imaging with little ambiguity. Some of the events are highlighted in Figure 1b; the grey areas and the letters indicate reflections, whereas red hyperbolas and the numbers indicate diffractions. Bad traces are killed.

With continued care, the velocity analysis is performed. Having identified the meaningful body-wave events, we look for them in the supergathers (Figure 2) and obtain the velocity from the best-fitting hyperbola. We iterate the velocity picking processed by using the velocity spectrum and the constant velocity stacks (CVS), till best result is achieved. As a priority, we ensure that the event is wellpicked and it appears both in the supergather and in the stacked section. Figure 3a shows the stacked time section and examples of several true events (the same events as in Figure 1b). We also produce a 


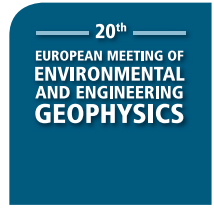

prestack-depth migrated section to account for the heterogeneity of the subsurface; the resulting depth section shows the main events and also the bottom of the landfill (see green line in Figure 3b). Note that not all events are uniformly mapped in the three images (Figure 1b, Figure 3a,b) because of the effect of the velocity analysis; especially in the case of the prestack-depth migration we use a simplified velocity model which performs well in general, but fails to image all events (e.g., event 3).
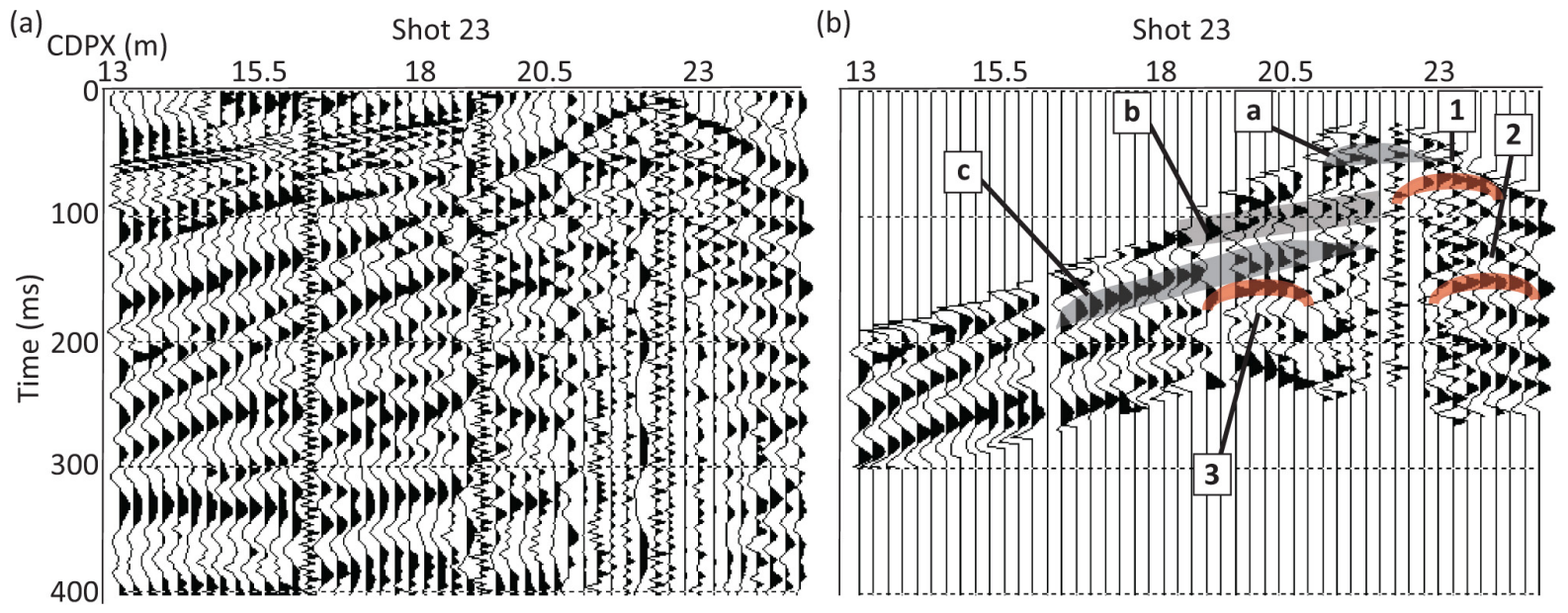

Figure 1 Seismic shot gather at position $23 \mathrm{~m}$ : (a) Raw and (b) processed. The grey-coloured areas and the letters show the position of reflections, whereas the red hyperbolas and the numbers show diffraction events.

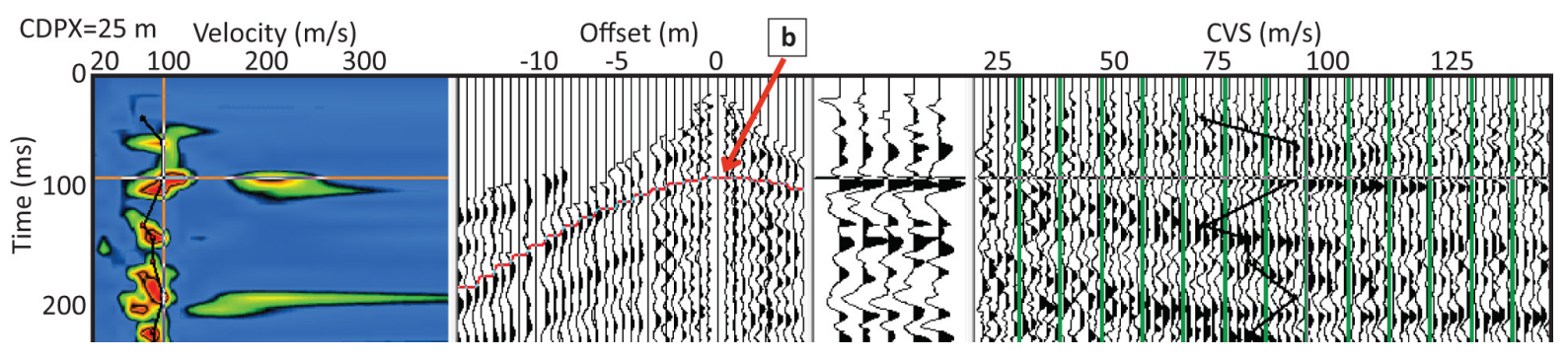

Figure 2 Example of velocity analysis in the case of a highly heterogeneous subsurface like a landfill. The red arrow indicates event $b$, used as a guide to illustrate the estimation of the correct velocity.
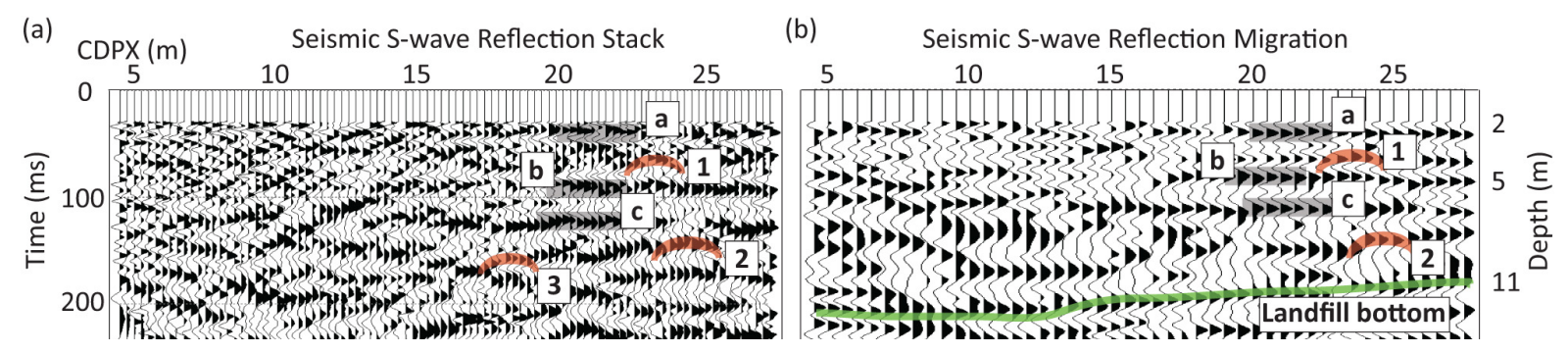

Figure 3 (a) Time-stacked section of shear-wave reflection data, (b) prestack depth-migrated section. The grey-coloured areas and letters show the position of reflections, whereas the red hyperbolas and numbers show diffraction events. The green line indicates the interpreted bottom of the landfill. 


\section{Results}

We use both electrical resistivity and seismic reflection data to interpret the heterogeneity in the body of the landfill. We obtain the electrical resistivity tomography (ERT) section by a joint inversion of the Wenner and dipole-dipole measurements, to improve the depth resolution (de la Vega et al. 2003). The interval S-wave velocity distribution obtained from velocity analysis and the ERT section are shown in Figure 4(a,b). The letters and the lines indicate the locations of possible dry or wet pockets. In a low resistivity area (e.g., the blue area above A), a higher concentration of leachate or water is expected (Cardimona 2002). We see that this area appears to end (e.g., below A where higher resistivity values are visible) at a location where a strong contrast in the S-wave velocity is present, indicating a higher-density zone acting as an obstruction to the leachate or water flow and hence creating a wet pocket.

The next step is to extract quantitative information about density and porosity heterogeneities. We calculate the density distribution using an empirical relationship, especially valid for landfill sites (Choudhury and Savoikar 2009), between unit weight $(\gamma)$ and S-wave velocity $\left(\mathrm{V}_{\mathrm{s}}\right)$ and the relationship between density $(\rho)$ and $\gamma$, where $g$ is the acceleration due to gravity $\left(9.81 \mathrm{~m} / \mathrm{s}^{2}\right)$ :

$\mathrm{V}_{\mathrm{s}}=1 /(0.0174-0.000978 \gamma)$ and $\gamma=\mathrm{g} \rho$

Choudhury and Savoikar (2009) have looked at more than 30 published articles that provide values of $\mathrm{V}_{\mathrm{s}}$ and $\gamma$ for landfills; their empirical relation is generally realistic for landfill sites. As input we use $\mathrm{V}_{\mathrm{s}}$ obtained from the seismic data and calculate the density distribution (Figure 4c). Then we use the relationship between porosity $(\varphi)$ and $\rho$ to calculate the porosity distribution (Figure $4 \mathrm{~d}$ ):

$\rho=(1-\varphi) \rho_{\mathrm{dry}}+S_{\mathrm{w}} \rho_{\mathrm{w}} \varphi$

For the dry density $\left(\rho_{\text {dry }}\right)$ we use an average value that we calculate based on the expected material composition in the Wieringermeer landfill (van Meeteren et al. 2009). $\rho_{\mathrm{w}}$ is the density of water; for water saturation $\left(\mathrm{S}_{\mathrm{w}}\right)$ we assume a value of 0 or 1 for electrical resistivity values higher or lower than $1.4 \mathrm{ohm}-\mathrm{m}$ respectively.

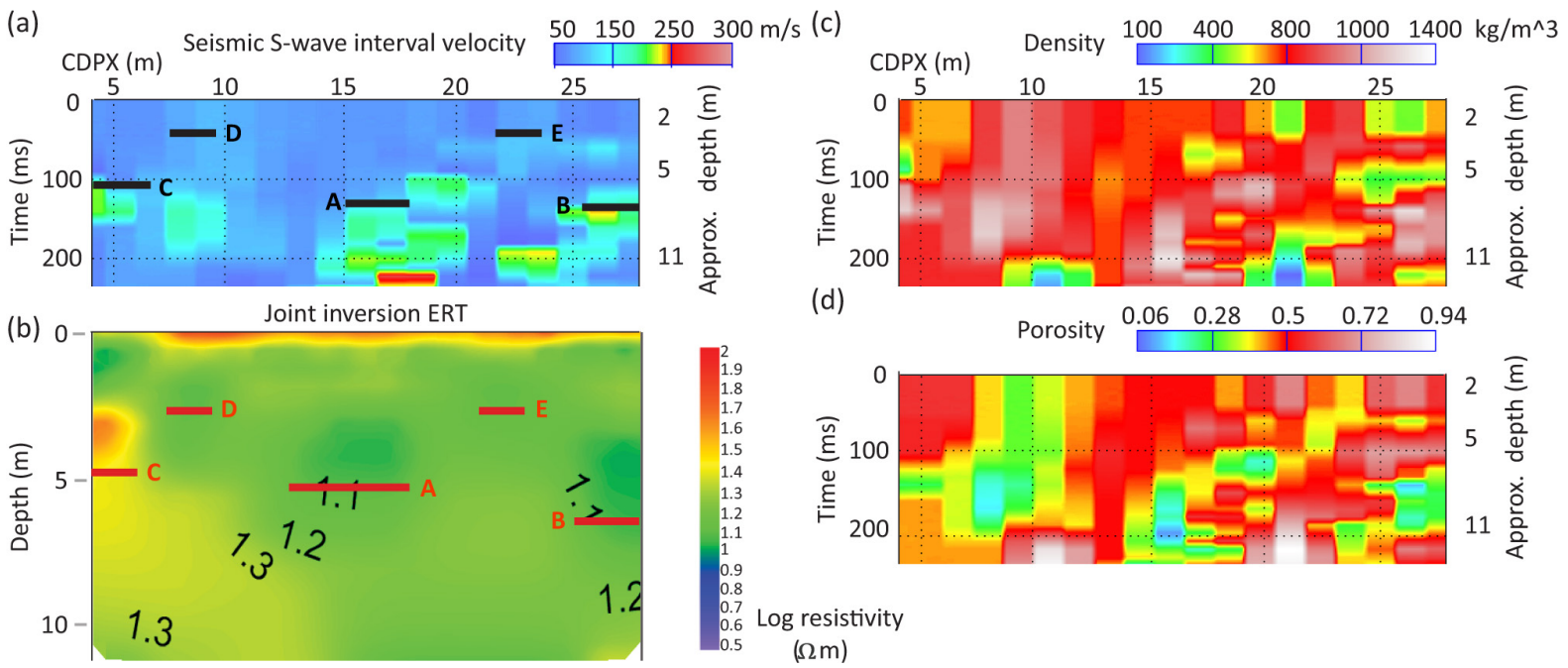

Figure 4 (a) Shear-wave velocity from seismics and (b) electrical resistivity from ERT. The letters and lines are showing possible wet and dry pockets. (c) Density and (d) porosity distribution.

\section{Discussion and conclusions}

We have presented a new methodology for imaging and characterizing a heterogeneous landfill. We have used both S-wave reflection and electrical resistivity data. The seismic data were very noisy. We have proposed an approach for processing the seismic reflection data at a noisy and heterogeneous 
landfill site, and obtain a high-resolution result. We have defined the location of wet or dry pockets, which will be beneficial for the improvement of landfill treatments. We have calculated density and porosity distributions in the landfill, which are important input parameters for modelling of the landfill behaviour in time. This can, in turn, help in enhancing the accuracy of estimation of the landfill after-care period.

Ground-rolls coming from a separate source in the field were a challenge in processing the shallow Swave reflection data. Through careful distinction of the meaningful body-wave events in the seismic data, we could overcome the problem and define the heterogeneity in the landfill. Uncertainty in the seismic velocity model is common; it was, however, possible to reduce this uncertainty by ensuring that all meaningful events were present both in the shot gathers and in the stacked section. Absence of extra ground-rolls will greatly help in obtaining better seismic images.

\section{Acknowledgements}

This research is supported by the Dutch Technology Foundation (STW) under the project number 11035. D.D. is supported by CATO2 and by the Division for Earth and Life Sciences (ALW) with financial aid from the Netherlands Organization for Scientific Research (NWO). Many thanks to Alber Hemstede, Michael Afanasyev, Shirish Baviskar, Andre van Turnhout, Asiya Kudarova and Andiry Bun for their help in the acquisition of the data.

\section{References}

Cardimona, S. [2002] Electrical resistivity techniques for subsurface investigation. http://www.dot.ca.gov/hq/esc/geotech/geo_support/geophysics_geology/documents/geophysic s 2002/061cardimona resistivity overview.pdf, accessed 7 March 2014.

Choudhury, D. and Savoikar, P. [2009] Simplified method to characterize municipal solid waste properties under seismic conditions. Waste Management, 29, 924-933.

De Iaco, R., Green, A. G., Maurer, H. R. and Horstmeyer, H. [2003] A combined seismic reflection and refraction study of a landfill and its host sediments. Journal of Applied Geophysics, 52(4), 139-156.

de la Vega, M., Osella, A. and Lascano, E. [2003] Joint inversion of Wenner and dipole-dipole data to study a gasoline-contaminated soil. Journal of Applied Geophysics, 54, 97-109.

Ghose, R. [2002] High-frequency shear wave reflections from shallow subsoil layers using a vibrator source: Sweep cross-correlation versus deconvolution with groundforce derivative. $72^{\text {nd }} S E G$ Annual Meeting, Expanded Abstracts,1408-1411.

Ghose, R. [2012] A micro-electromechanical system digital 3-C array seismic cone penetrometer. Geophysics, 77(3), WA99-WA107.

Ghose, R., Brouwer, J. and Nijhof, V. [1996] A portable S-wave vibrator for high-resolution imaging of the shallow subsurface. $58^{\text {th }}$ EAGE Conference \& Exhibition, Extended Abstracts, M037.

Jolly, J.M., Barker, R.D. and Beaven, R.P. [2011] Resolution of electrical imaging of fluid movement in landfills. Proceedings of the ICE - Waste and Resource Management, 164(2), 79-96.

McDougall, J.R. and Fleming, I.R. [2013] Hydro-bio-mechanical modelling of filling and post closure landfill behaviour - a case study. HPM5 - Fifth International workshop on Hydro-physicomechanics of landfills, 77-87.

Powrie, W. and Beaven, R.P. [1999] Hydraulic properties of household waste and implications for landfills. Proceedings of the ICE - Geotechnical Engineering, 137(4), 235-247.

Staub, M., Galietti, B., Oxarango, L., Khire, M.V. and Gourc, J.P. [2009] Porosity and hydraulic conductivity of MSW using laboratory - scale tests. HPM3 - Third international conference on Hydro-Physico-Mechanics of landfills, 1-9.

van Meeteren, M., Timens, D. and Heyer, K. U. [2009] Feasibility study sustainable emission reduction at the existing landfills Kragge and Wieringermeer in the Netherlands: Current status of landfill Wierengermeer. Royal Haskoning. 